\title{
The Response of Pavement to The Multi-Axle Vehicle Dynamic Load
}

\author{
Y. Chen, H. Zhang, X.Q. Zhu, D.W. Liu \\ Qingdao University \\ Qingdao, China
}

\begin{abstract}
In order to study the response of pavement to the multi-axle vehicle dynamic load, three-dimensional finite element analysis model of asphalt pavement under a multi-axle vehicle dynamic load was established. The structure of asphalt pavement simplified to four layers. The material of asphalt surface layer has the property of viscoelastic and the materials of the other layers are assumed to be linear elastic. The results can provide a reference for the design and analysis of pavement performance and pavement structure.
\end{abstract}

Keywords-multi-axle vehicle; asphalt pavement; viscoelastic; dynamic response

\section{INTRODUCTION}

When the asphalt pavement structure and performance was designed and analysed, the response of asphalt pavement under the vehicle dynamic load must be understood to ensure the pavement life. Most previous studies were based on the elastic layered structure theory, which regarded the asphalt pavement layered as linear elastic structure to study dynamic response of pavement under the role of uniaxial or biaxial vehicle tires[1-2]. To accurately simulate and predict dynamic response of pavement caused by vehicle, the viscoelastic and nonlinear of asphalt pavement structure has been considered. Khavassefat considered viscoelastic of asphalt pavement surface layer to establish a three-dimensional finite element model of the road. It analysed the response characteristics of asphalt pavement stress and strain under different speed of vehicle load [3]. Ambassa considered viscoelastic of asphalt pavement surface layer to establish a three-dimensional finite element model of the road. It predicted fatigue damage characteristics of pavement under multi-axle moving loads [4]. However, these studies are lack of research on the dynamic response of pavement under triaxial heavy vehicles load. These are difficult to fully analyse the impact of pavement performance under dynamic load. Based on this, the asphalt pavement dimensional finite element model considering viscoelastic was established in this paper, to analyse the response of pavement to a multi-axle vehicle dynamic load, which provided a reference for the design and analysis of pavement performance and pavement structure.

\section{Finite Element ANALysis Model of Asphalt PAVEMENT UNDER VEHICLE DYNAMIC LOAD}

Currently, the common used finite element analysis softwares in pavement performance study are ABAQUS, ANSYS, ADINA, etc. In which, ABAQUS developed by the
United States HKS is widely used in pavement performance study [5-6]. Therefore, we chose ABAQUS finite element software to build a three-dimensional finite element model of asphalt pavement under the vehicle dynamic load.

\section{Finite ElEment ANAlysis Model of Asphalt PAVEMENT UNDER VEHICLE DYNAMIC LOAD}

Asphalt pavement is a kind of pavement structure on witch paves a certain thickness of asphalt on the flexible and semirigid base as the surface layer. The structure of asphalt pavement is generally simplified as four layers in the analysis of pavement performance: Asphalt surface, base course, sub base course and soil base course. In which the asphalt surface layer has the property of viscoelastic. Each layer of material has a different material property. The parameters of road model [7] are shown in Table 1.

TABLE I. THE PARAMETERS OF ASPhalt PAVEMENT MODEL

\begin{tabular}{|c|l|l|l|l|l|}
\hline Layer & $\begin{array}{c}\text { Thickn } \\
\text { ess } \\
(\mathbf{m})\end{array}$ & $\begin{array}{c}\text { Elastic } \\
\text { Modulus } \\
\boldsymbol{E}(\mathbf{M P a})\end{array}$ & $\begin{array}{c}\text { Poisson } \\
\text { 's ratio } \\
\boldsymbol{v}\end{array}$ & $\begin{array}{c}\text { Densit } \\
\mathbf{y} \boldsymbol{\rho} \\
\left(\mathbf{k g} / \mathbf{m}^{3}\right)\end{array}$ & $\begin{array}{c}\text { Dampi } \\
\mathbf{n g} \\
\text { rate \% }\end{array}$ \\
\hline $\begin{array}{c}\text { Asphal } \\
\mathbf{t} \\
\text { surface }\end{array}$ & 0.1 & $/$ & 0.3 & 2613 & 0.05 \\
\hline $\begin{array}{c}\text { Base } \\
\text { course }\end{array}$ & 0.15 & 1327 & 0.3 & 2210 & 0.05 \\
\hline $\begin{array}{c}\text { Sub } \\
\text { base } \\
\text { course }\end{array}$ & 0.3 & 305 & 0.35 & 1980 & 0.05 \\
\hline $\begin{array}{c}\text { Soil } \\
\text { Base } \\
\text { course }\end{array}$ & 9.45 & 60 & 0.4 & 1380 & 0.05 \\
\hline
\end{tabular}

The viscoelastic of asphalt surface layer could be characterized by the Prony series of ABAQUS software. Base course, sub base course and soil base course could be simulated by linear elastic simulation.

We choose the road with $100 \mathrm{~m}$ long, $18 \mathrm{~m}$ wide, and $10 \mathrm{~m}$ deep in this article. Using the Part Module to establish a flexible pavement model and split the pavement model in different structural layers, each layer was given a different section properties and material properties. Sowing seeds at different parts in different density and meshing in the Mesh Module. When meshing, we use the C3D8R hexahedral element with $0.2 \mathrm{~m}$ in length direction. The density of width direction is depended on the action position of both sides of the wheel. In the operative position of the wheel, the density of mesh is denser than other area, the minimum size is $0.15 \mathrm{~m}$, the maximum size of $0.6 \mathrm{~m}$.In depth direction, the mesh density of 
asphalt surface is $0.033 \mathrm{~m}$, base course is $0.05 \mathrm{~m}$, sub base course is $0.075 \mathrm{~m}$, and soil base course is $3.15 \mathrm{~m}$. When the vehicle is traveling on the road, the dynamic response is small at the two ends of road. According to Saint-Venant principle, the sides, bottom and both ends of the road constraints are considered fixed. The total number of elements of the entire model is 462000 , and the number of nodes is 495489 . Asphalt Pavement finite element model is shown in Figure 1.

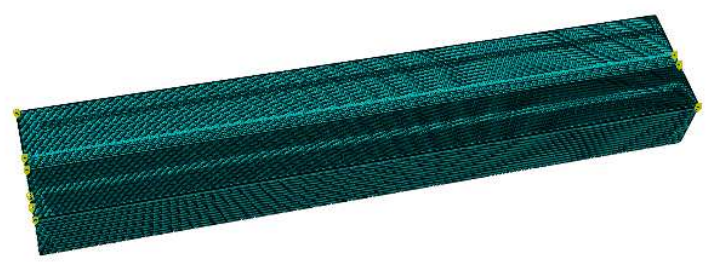

FIGURE I. THE FINITE ELEMENT MODEL OF ASPHALT PAVEMENT

\section{Grounding Pressure of Tires AND LoAding Method}

A dump truck used during the Finite element analysis is manufactured by a company, whose structure is $6 \times 4$. Its full quality is $26000 \mathrm{~kg}$ and the front axle load weight is $6000 \mathrm{~kg}$, the real axle is $10000 \mathrm{~kg}$. The tire pressure is $0.93 \mathrm{MPa}$. Within the contact patch of tires, tire pressure asymmetrically distributed both in the longitudinal and transverse. In this paper, the tire pressure is assumed to be uniformly distributed in the grounding area. Contact area dimensions remain unchanged in each transient state while the tire pressure moving in the pavement [8]. In order to facilitate the finite element analysis, the contact area of front and rear tires with the road surface were simplified as rectangles, whose sizes are $0.21 \times 0.15 \mathrm{~m}$ and $0.19 \times 0.27 \mathrm{~m}$. Grounding areas are $0.031 \mathrm{~m} 2$ and $0.051 \mathrm{~m} 2$.

To simulate the effect of dead load during vehicle movement, use vdload subprogram in ABAQUS to apply the moving load on semi-rigid asphalt pavement finite element model. ABAQUS provides for users with a powerful and flexible user subroutine interfaces. Vdload subroutine can be used to define a set of functions with respect to the position, speed and time, the applied load. It can very well simulate the vertical pressure in the moving loading process. The frequency of the tire normal force for solving is $170.5 \mathrm{~Hz}$ when the speed is $60 \mathrm{~km} / \mathrm{h}$. Time interval is $0.0058 \mathrm{~s}$. Every load achieved during this time interval is unchanged. And another set of values are taken in the next time interval. Vehicle dynamic load is the basis of static load multiplied by the dynamic load factor and then applied to the model [9].

\section{Finite ElEMENT MEthod (FEM) RESUlts AND ANALysis}

\section{A. Vertical Stress of Pavement}

The vertical stress contour of a determining position of asphalt surface under vehicle dynamic load is shown in Figure 2.
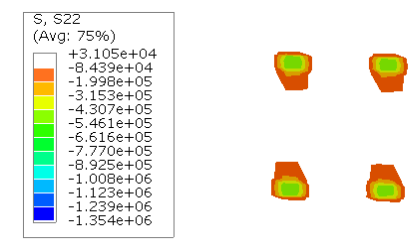

FIGURE II. VERTICAL STRESS CONTOUR OF ASPHALT SURFACE

It is shown in Figure 2 that there are two tires on both sides of the mid-axle and rear axle and there is a single tire on both sides of the front axle, the range of the pressure that the front axle wheels produce is smaller, thus resulting in greater stress.

The vertical stress time history curves of a determining position of the asphalt surface and a bottom surface under dynamic load of the right wheels are shown in Figure 3.

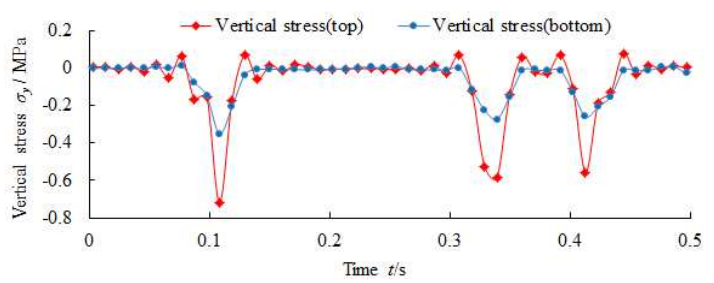

FIGURE III. THE TIME HISTORY CURVES OF VERTICAL STRESS

As can be seen from Figure 3, on a specific location of the road, vertical compressive stress is greater than the vertical stress tensile stress and there are three peaks of vertical compressive stress. Three peaks of vertical compressive stress were the stress of the front, axial and rear axle wheels when the vehicle passing. The value of three stresses is different because the loads of three axle wheels are different. As for asphalt surface, with the wheel off and near a specific location of the road, it appears vertical tensile stress in the asphalt surface layer because the pushing and compaction of the wheels, but the vertical tensile stress is much smaller than the vertical stress. It can also be seen in Figure 3 that the vertical stress of the bottom surface of the asphalt layer is less than the asphalt surface.

\section{B. Longitudinal Stress of Pavement}

The longitudinal stress contour of a determining position of asphalt surface under vehicle dynamic load is shown in Figure 4.

It is shown in Figure 4 that because the wheels of each axis and the wheels on both sides produce a coupling action, the distribution of longitudinal compressive stress is greater than the vertical compressive stress.
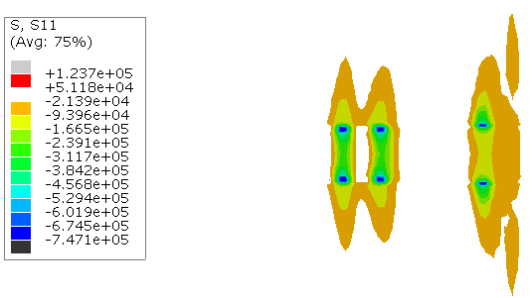

FIGURE IV.

LONGITUDINAL STRESS CONTOUR OF ASPHALT SURFACE 
The longitudinal stress time history curves of a determining position of asphalt surface and bottom surface under dynamic load of the right wheels are shown in Figure 5.

As can be seen from Figure 5, the longitudinal stress trends of asphalt surface layer and the bottom surface layer are different under moving dead loads. There has been a state of tension and compression alternating stress on the asphalt bottom surface layer. It makes that the asphalt bottom surface layer prones to fatigue cracking and gradually spreads to the upper. Eventually the entire asphalt surface occurred breakage.

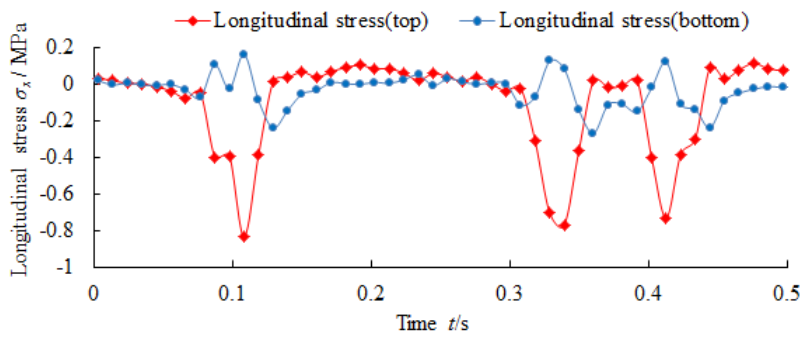

FIGURE V. THE TIME HISTORY CURVES OF LONGITUDINAL STRESS

\section{Transverse Stress of Pavement}

The transverse stress contour of a determining position of asphalt surface under vehicle dynamic load is shown in Figure 6.

It is shown in Figure 6 that the distribution and value of transverse compressive stress are greater than the vertical stress in effect of the wheels, but the value of transverse compressive stress is less than the vertical stress.

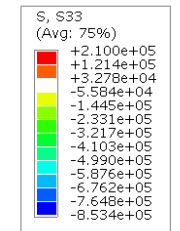

FIGURE VI
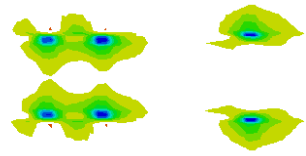

\section{TRANSVERSE STRESS CONTOUR OF ASPHALT} SURFACE

The transverse stress time history curves of a determining position of the asphalt surface and a bottom surface under dynamic load of the right wheels are shown in Figure7.

As can be seen from Figure 7, the transverse stress trend of asphalt surface layer and bottom surface is different. There has been a state of tension and compression alternating stress on the asphalt bottom surface layer. It makes that the asphalt bottom surface layer prones to fatigue cracking and gradually spreads to the upper. Eventually the entire asphalt surface occurred breakage.

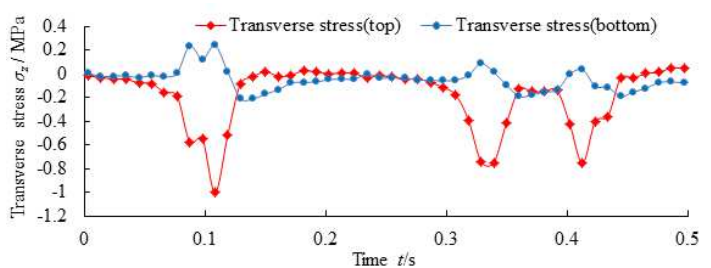

FIGURE VII

THE TIME HISTORY CURVES OF TRANSVERSE STRESS

\section{CONCLUSION}

We use the three-dimensional finite element model of asphalt pavement established under vehicle dynamic load to get the dynamic response of road under dynamic load, the results showed that:

(1)The wheel of the front axle could produce higher stress at the smaller sphere of action. The distribution rang of longitudinal compressive stress is larger than vertical stress, for the coupling effect between each wheel of shafts and both sides of wheels. The distribution rang and value of transverse compressive stress where the wheel and the ground interact is larger than the longitudinal compressive stress, but the value of transverse compressive stress is lesser than the vertical compressive stress.

(2)The vertical compressive stress of asphalt layer is larger than the vertical tensile stress, and there are three peaks in vertical compressive stress. The three peaks of vertical compressive stress are produced when the wheel of the front axle, central axis and rear axle passing. The alternating tension and compression stress state appears in the bottom layer of asphalt. It could cause the fatigue cracking in the bottom layer of asphalt, and the fatigue cracking gradually spread to the top. Finally, the breakage appears in the entire asphalt surface.

\section{ACKNOWLEDGEMENTS}

The research supported by Shandong provincial Natural Science Foundation and Qingdao University Excellent Postgraduate Thesis Nurture Project (Grant No. 51475248)

\section{REFERENCES}

[1] Chen Jing, Liu Dawei, Huo Wei, Chen Bingcong, Response of pavement to vehicle dynamic load. Transactions of the Chinese Society for Agricultural Machinery, 32(2), pp.11-14, 2002.

[2] Shan Jingsong, Huang Xiaoming, Liao Gongyun, Dynamic response analysis of pavement structure under moving load. Journal of highway and transportation research and development,24(1), pp.10-13,2007.

[3] Khavassefat P, Jelagin D, Birgisson B. A computational framework for viscoelastic analysis of flexible pavements under moving loads. Materials and structures, 45(11), pp.1655-1671, 2012.

(a) Ambassa Z, Allou F, Petit C, et al. Fatigue life prediction of an asphalt pavement subjected to multiple axle loadings with viscoelastic FEM. Construction and Building Materials, 43, pp. 443-452, 2013.

[4] De Beer M, Fisher C, Jooste F J. Evaluation of non-uniform tyre contact stresses on thin asphalt pavements. Ninth International Conference on Asphalt Pavements, 2002(5), pp. 19-22.

[5] Liu M, Huang X, TAO X. FEM Analysis of Dynamic Response of Pavement Adjacent to Abutment under Moving Load. Journal of Highway and Transportation Research and Development, 2006(5), pp.57-62. 
[6] Lee J, Kim J, Kang B. Normalized resilient modulus model for subbase and subgrade based on stress-dependent modulus degradation. Journal of Transportation Engineering, 135(9), pp.600-610, 2009.

[7] Sun L, Kenis W, Wang W. Stochastic spatial excitation induced by a distributed contact on homogenous gaussian random fields. Journal of engineering mechanics, 132(7), pp.714-722, 2006.

[8] Liu Dawei, Jiang Rongchao, Chen Huanming. Simulation of dynamic load for heavy vehicle under bilateral tracks' road excitation. Advances in Civil Engineering and Building Materials - Selected Peer Reviewed Papers from 2012 2nd International Conference on Civil Engineering and Building Materials, pp. 883-886, 2012. 